\title{
The efficacy and safety of apatinib for refractory malignancies: a review and meta-analysis
}

This article was published in the following Dove Press journal: OncoTargets and Therapy

\section{Dantong Sun \\ Helei Hou \\ Chuantao Zhang \\ Xiaochun Zhang}

Department of Medical Oncology, The Affiliated Hospital of Qingdao University, Qingdao University, Qingdao 266003, China
Correspondence: Xiaochun Zhang Department of Medical Oncology, The Affiliated Hospital of Qingdao University, Qingdao University, 16 Jiangsu Road, Qingdao 266003, China Email zxc9670@qdu.edu.cn
Background and purpose: Apatinib is a novel, oral, small-molecule tyrosine kinase inhibitor that targets VEGFR-2. Recent clinical trials have revealed its broad-spectrum anticancer effect. However, most recent studies of apatinib have involved single-arm studies with insufficient cases, different doses of drugs, and different incidences of adverse events (AEs), which has resulted in a lack of accurate measurement of the efficacy and safety of apatinib. Thus, we performed this meta-analysis to evaluate the efficacy and safety of apatinib.

Methods: In total, 21 studies from five databases (PubMed, ScienceDirect, ClinicalTrials.gov, China National Knowledge Infrastructure $[\mathrm{CNKI}]$, and Cochrane Library) were included in this meta-analysis. All statistical analyses in this meta-analysis were performed using Stata 14.0 software. We used objective response rate (ORR) and disease control rate (DCR) to evaluate the efficacy of apatinib for five major types of solid tumors. Additionally, we used the total incidence of AEs and the incidence of the three most common grade 3-4 AEs to evaluate the safety of apatinib.

Results: The pooled results for the efficacy of apatinib in the treatment of different types of solid tumors revealed that patients treated with apatinib exhibited good disease control. In addition, it was likely that an increased dose of apatinib resulted in an increased ORR in lung and breast cancer and an increased DCR in liver and gastric cancer. Although AEs appeared in $84 \%$ of patients included in this meta-analysis, most of these AEs were of grades 1-2 and were well tolerated and controlled. The most common grade 3-4 AEs included hypertension, hand-foot syndrome, and proteinuria. Importantly, there were no significant differences in these grade 3-4 AEs with higher doses of apatinib.

Conclusion: Apatinib is a novel VEGFR-2 inhibitor with proven efficacy and safety for solid tumors. The meta-analysis reveals the broad-spectrum anticancer effect of apatinib.

Keywords: apatinib, solid tumors, objective response rate, disease control rate, adverse events

\section{Background and purpose}

The incidence of malignant tumors has increased rapidly in recent years, especially in China. According to a report on cancer incidence and mortality in different areas of China, 3.8 million new malignant tumor cases were diagnosed in 2014. The crude incidence of malignant tumors in 2014 was $278.1 / 10^{5}$, whereas the crude mortality was $167.89 / 10^{5} .{ }^{1}$ Therefore, more effective cancer treatments are needed.

VEGF was first identified by Folkman et al in the 1970s. ${ }^{2}$ Briefly, VEGF, which is mitogenic for endothelial cells and is responsible for the formation of new capillaries, plays an important role in tumor growth and metastasis. ${ }^{2,3}$ The physiological VEGF family consists of six growth factors, namely VEGF-A, VEGF-B, VEGF-C, 
VEGF-D, VEGF-E, and PLGF. The VEGFR family includes three protein tyrosine kinases: VEGFR-1 (Flt-1), VEGFR-2 (Flt-1/KDR), and VEGFR-3 (Flt-4). The combination of VEGF and VEGFR induces angiogenesis and vasculogenesis through p38MAPK, Raf/MEK/ERK, and PI3K/PKB signaling pathways. ${ }^{4,5}$ Given that VEGFR-2 plays a more important role in the signaling pathways, small-molecule tyrosine kinase inhibitors mostly target VEGFR-2.

Apatinib, also known as YN968D1, is a novel, oral, smallmolecule tyrosine kinase inhibitor that targets VEGFR-2 as well as c-Kit and c-SRC tyrosine kinases. ${ }^{6}$ Apatinib was approved and launched in China in 2014 for subsequentline treatment of gastric cancer. ${ }^{7}$ Recent clinical trials have revealed its broad-spectrum anticancer effect. However, most recent studies of apatinib have involved single-arm studies with insufficient cases, different doses of drugs, and different incidences of adverse events (AEs), resulting in a lack of accurate measurement of the efficacy and safety of apatinib. Thus, we performed this meta-analysis to evaluate the efficacy and safety of the novel VEGFR-2 inhibitor apatinib.

\section{Methods}

\section{Search strategy for studies}

From April 2018 to May 2018, two authors (Sun DT and Hou HL) searched five databases independently, namely PubMed, ScienceDirect, ClinicalTrials.gov, China National Knowledge Infrastructure (CNKI), and Cochrane Library. All MeSH terms of the keywords (apatinib, YN968D1) were used in the search.

Any disagreement regarding study inclusion was resolved through discussion by all authors. In addition, we contacted the corresponding authors of some of the studies if the databases failed to provide sufficient information.

\section{Literature selection criteria}

All clinical trials that evaluated the efficacy and safety of apatinib in the treatment of solid tumors were considered eligible for the analysis. Two authors (Sun DT and Hou HL) completed the screening of the literature independently. The inclusion criteria were as follows: 1) study types - Phase II clinical trials or retrospective analysis; 2) participant types patients with solid tumors; 3) intervention types - patients were treated with apatinib only with different doses; 4) outcome measure types - disease control rate (DCR), objective response rate (ORR), the incidence of $\geq$ grade 3 AEs, or at least one of these outcomes should be provided in the included studies; and 5) full text was available.
The exclusion criteria were as follows: studies were case reports, reviews, or meta-analyses, duplicates, or involved animal or cell experiments, and full text was not available via other means.

\section{Data extraction}

Two authors (Sun DT and Hou HL) completed the related literature data extraction independently. The following data were extracted: study ID, cancer types, number of patients, dose and frequency of apatinib treatment, disease baseline before apatinib treatment, Eastern Cooperative Oncology Group status, and study phase. The details of the 21 studies included ${ }^{8-28}$ are presented in Table 1. In addition, we extracted the research indicators selected by this meta-analysis, including ORR (ORR = complete response $[\mathrm{CR}]+$ partial response $[\mathrm{PR}]), \mathrm{DCR}(\mathrm{DCR}=$ $\mathrm{CR}+\mathrm{PR}+$ stable disease), and the incidence of $\geq$ grade 3 AEs. The results of data extraction were discussed by all authors.

\section{Quality assessment}

Two authors (Zhang CT and Zhang XC) assessed the quality of the studies independently after reading the full text of each study. We used the Newcastle-Ottawa Scale (NOS) to assess the quality of non-randomized controlled trials in this metaanalysis. ${ }^{29}$ The quality of a study was considered "poor" if the NOS score was $<4$. If the score was $4-6$, we considered the study to be of "moderate" quality. A study with a score of 7-9 was considered to be of "high quality". The NOS scores of the 21 studies included are presented in Table 1, and the quality assessment details are presented in Table 2 .

\section{Statistical analysis}

All statistical analyses in this meta-analysis were performed using Stata 14.0 software (Stata Corp., College Station, TX, USA). The results were expressed as incidences and 95\% CIs. In this meta-analysis, we used a random-effect model to perform the statistical analyses, and chi-squared test and $I^{2}$ statistic were used to assess the inter-study heterogeneity. A $P$-value $>0.1$ and $I^{2}<50 \%$ indicated that the heterogeneity was not statistically significant. If the $P$-value was $<0.1$ and $I^{2}$ was $>50 \%$, significant heterogeneity was noted between the studies. Therefore, subgroup analyses were used to assess the heterogeneity. Begg's and Egger's tests were used to evaluate the publication bias in this meta-analysis.

\section{Meta-analysis results}

Figure 1 presents the flowchart of selection of the 21 included studies. A total of 879 references were identified after database 
Table I Main characteristics of the included studies

\begin{tabular}{|c|c|c|c|c|c|c|c|}
\hline Study & Cancer type & $\begin{array}{l}\text { Number of } \\
\text { patients }\end{array}$ & $\begin{array}{l}\text { Dose and } \\
\text { frequency }\end{array}$ & Disease baseline & $\begin{array}{l}\text { ECOG } \\
\text { status }\end{array}$ & $\begin{array}{l}\text { Study } \\
\text { phase }\end{array}$ & $\begin{array}{l}\text { Quality } \\
\text { assessment } \\
\text { (NOS) }\end{array}$ \\
\hline Hu et al $(20 \mid 4)^{8}$ & Breast cancer & 38 & $500 \mathrm{mg}, \mathrm{po}, \mathrm{qd}$ & Treatment failure and metastasis & $0-1$ & II & 6 \\
\hline Liu and $\mathrm{Wu}(2017)^{9}$ & Breast cancer & 20 & $850 \mathrm{mg}, \mathrm{po}, \mathrm{qd}$ & Treatment failure and metastasis & $0-1$ & II & 6 \\
\hline Yuan et al $(2017)^{10}$ & Breast cancer & 27 & $425 \mathrm{mg}$, po, qd & Treatment failure and metastasis & $\mathrm{I}-2$ & NA & 6 \\
\hline Shi et al $(2017)^{\prime \prime}$ & Lung cancer & 72 & $250 \mathrm{mg}, \mathrm{po}, \mathrm{qd}$ & $\begin{array}{l}\text { TNM staging: Illb-IV } \\
\text { Treatment failure }\end{array}$ & $0-2$ & II & 5 \\
\hline Jiao and $\mathrm{Li}(2017)^{12}$ & Lung cancer & 42 & $500 \mathrm{mg}, \mathrm{po}, \mathrm{qd}$ & Treatment failure and metastasis & NA & NA & 5 \\
\hline Yang $(2017)^{13}$ & Lung cancer & 30 & $500 \mathrm{mg}$, po, qd & $\begin{array}{l}\text { TNM staging: Illb-IV; } \\
\text { Treatment failure and metastasis }\end{array}$ & $\mathrm{I}-2$ & II & 5 \\
\hline Li et al $(2016)^{14}$ & Lung cancer & 22 & $425 \mathrm{mg}, \mathrm{po}, \mathrm{qd}$ & $\begin{array}{l}\text { TNM staging: Illb-IV; } \\
\text { Treatment failure and metastasis }\end{array}$ & $\mathrm{I}-2$ & II & 5 \\
\hline Nie et al $(2017)^{15}$ & Lung cancer & 28 & $500 \mathrm{mg}$, po, qd & $\begin{array}{l}\text { TNM staging: IV; } \\
\text { Treatment failure and metastasis }\end{array}$ & $0-2$ & II & 5 \\
\hline Fang et al $(2018)^{16}$ & Lung cancer & 36 & $500 \mathrm{mg}, \mathrm{po}, \mathrm{qd}$ & Treatment failure and metastasis & $0-2$ & II & 5 \\
\hline Ruan et al $(2017)^{17}$ & Gastric cancer & 42 & $850 \mathrm{mg}, \mathrm{po}, \mathrm{qd}$ & Treatment failure and metastasis & $\mathrm{I}-2$ & II & 6 \\
\hline Zhang et al $(2018)^{18}$ & Gastric cancer & 23 & $500 \mathrm{mg}, \mathrm{po}, \mathrm{qd}$ & Treatment failure and metastasis & $0-1$ & NA & 6 \\
\hline Zhang et al $(2016)^{19}$ & Gastric cancer & 20 & $500 \mathrm{mg}, \mathrm{po}, \mathrm{qd}$ & $\begin{array}{l}\text { TNM staging: IV; } \\
\text { Treatment failure and metastasis }\end{array}$ & NA & NA & 5 \\
\hline Yao et al $(2017)^{20}$ & Gastric cancer & 30 & $500 \mathrm{mg}, \mathrm{po}, \mathrm{qd}$ & Treatment failure and metastasis & $1-3$ & NA & 5 \\
\hline Lang et al $(2017)^{21}$ & Gastric cancer & 14 & $850 \mathrm{mg}, \mathrm{po}, \mathrm{qd}$ & $\begin{array}{l}\text { TNM staging: IV; } \\
\text { Treatment failure and metastasis }\end{array}$ & NA & NA & 5 \\
\hline Yu et al $(20 \mid 8)^{22}$ & Liver cancer & 31 & $250 \mathrm{mg}, \mathrm{po}, \mathrm{qd}$ & Treatment failure and metastasis & NA & II & 6 \\
\hline Song et al $(2017)^{23}$ & Liver cancer & $\begin{array}{l}\text { a: } 15 \\
\text { b: } 25 \\
\text { c: } 13\end{array}$ & $\begin{array}{l}\text { a: } 250 \mathrm{mg}, \mathrm{po}, \\
\text { qd b: } 500 \mathrm{mg}, \\
\text { po, qd c: } 850 \\
\mathrm{mg}, \mathrm{po}, \mathrm{qd}\end{array}$ & Treatment failure & $2-4$ & NA & 6 \\
\hline Qin et al $(2017)^{24}$ & Liver cancer & $\begin{array}{l}\text { a: } 53 \\
\text { b: } 51\end{array}$ & $\begin{array}{l}\text { a: } 850 \mathrm{mg}, \mathrm{po}, \\
\text { qd b: } 750 \mathrm{mg} \text {, } \\
\text { po, qd }\end{array}$ & Treatment failure and metastasis & $0-1$ & II & 6 \\
\hline Liang et al $(2018)^{25}$ & $\begin{array}{l}\text { Colorectal } \\
\text { cancer }\end{array}$ & 36 & $\begin{array}{l}\text { 425-750 mg, } \\
\text { po, qd }\end{array}$ & Treatment failure and metastasis & $0-1$ & NA & 6 \\
\hline Gou et al $(2018)^{26}$ & $\begin{array}{l}\text { Colorectal } \\
\text { cancer }\end{array}$ & 36 & $250 \mathrm{mg}$, po, qd & Treatment failure and metastasis & $\begin{array}{l}0-1: 69.4 \% \\
\geq 2: 30.6 \%\end{array}$ & NA & 5 \\
\hline Sun et al $(2017)^{27}$ & $\begin{array}{l}\text { Colorectal } \\
\text { cancer }\end{array}$ & 14 & $425 \mathrm{mg}, \mathrm{po}, \mathrm{qd}$ & $\begin{array}{l}\text { TNM staging: IV; } \\
\text { Treatment failure and metastasis }\end{array}$ & $\mathrm{I}-2$ & II & 5 \\
\hline Wang et al $(2017)^{28}$ & $\begin{array}{l}\text { Colorectal } \\
\text { cancer }\end{array}$ & 17 & 500 mg, po, qd & $\begin{array}{l}\text { TNM staging: IV; } \\
\text { Treatment failure and metastasis }\end{array}$ & $0-3$ & NA & 5 \\
\hline
\end{tabular}

Abbreviations: ECOG, Eastern Cooperative Oncology Group; NA, not applicable; NOS, Newcastle-Ottawa Scale; po, orally; qd, once a day.

searches (PubMed 166, CNKI 329, Cochrane Library 47, ScienceDirect 150, ClinicalTrials.gov 187). Then, 537 references remained after duplicates were removed. Twenty-nine references remained after the first screening. Eight studies were excluded based on the following reasons: four were case reports or case series, one was a duplicate, and three involved cell experiments. Finally, 21 studies with a total of 735 patients were included for the assessment of efficacy and safety of apatinib.

\section{The efficacy of apatinib}

\section{Apatinib in lung cancer}

Six studies with a total of 230 patients evaluated the efficacy of apatinib in lung cancer. The pooled DCR of apatinib for lung cancer patients was 82\% (95\% CI: 77\%-87\%; Figure 2A). The pooled ORR of apatinib for lung cancer patients was 20\% (95\% CI: 14\%-25\%). Subgroup analysis revealed that patients who were administered a $500 \mathrm{mg}$ dose of apatinib exhibited an increased ORR compared with patients who received a $<500 \mathrm{mg}$ dose $(23 \%, 95 \% \mathrm{CI}$ : $16 \%-29 \%$ vs $16 \%$, 95\% CI: $8 \%-23 \%$; Figure $2 \mathrm{~B}$ ).

\section{Apatinib in liver cancer}

Three studies with a total of 188 patients evaluated the efficacy of apatinib in liver cancer. The pooled DCR of apatinib for liver cancer patients was 51\% (95\% CI: 37\%-64\%). Subgroup analysis revealed that patients who received $\geq 750 \mathrm{mg}$ apatinib 


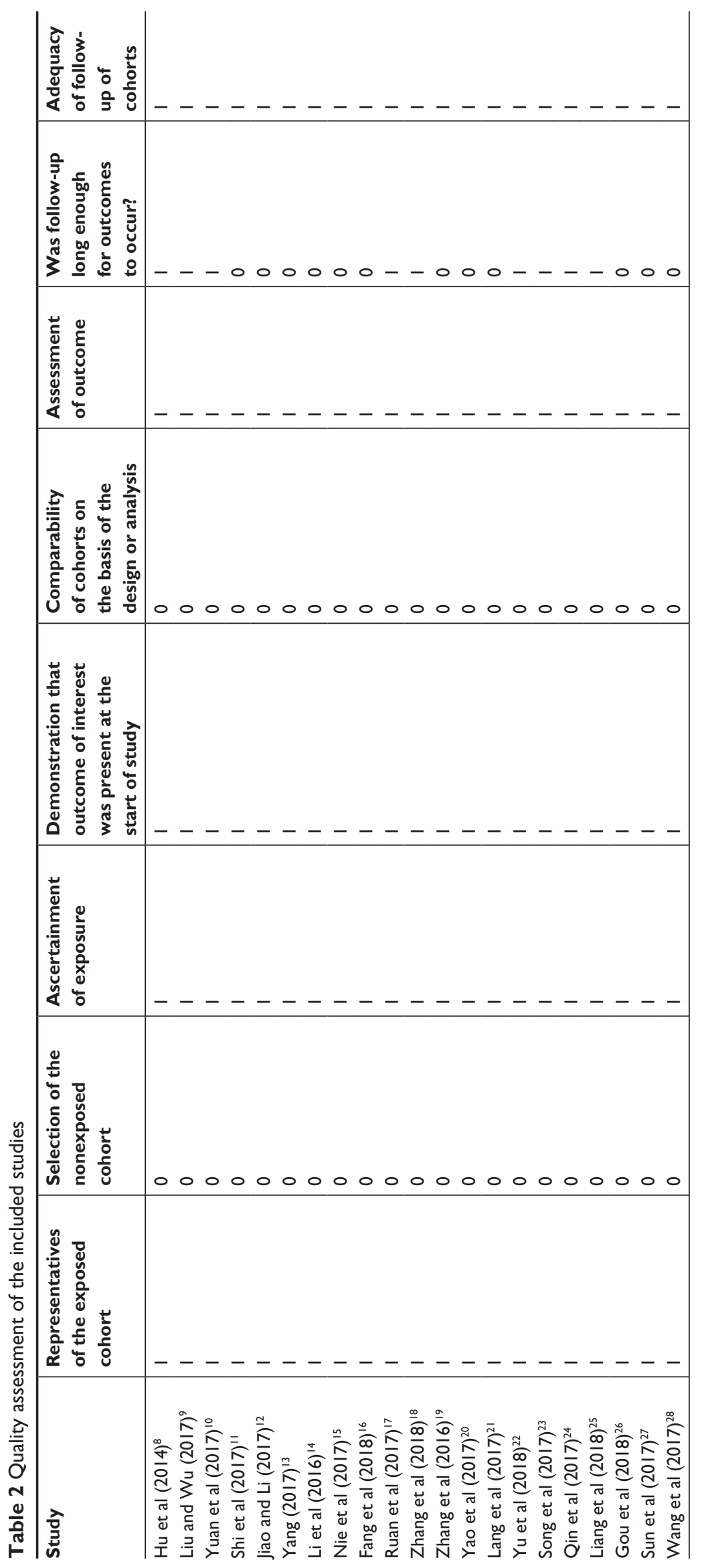




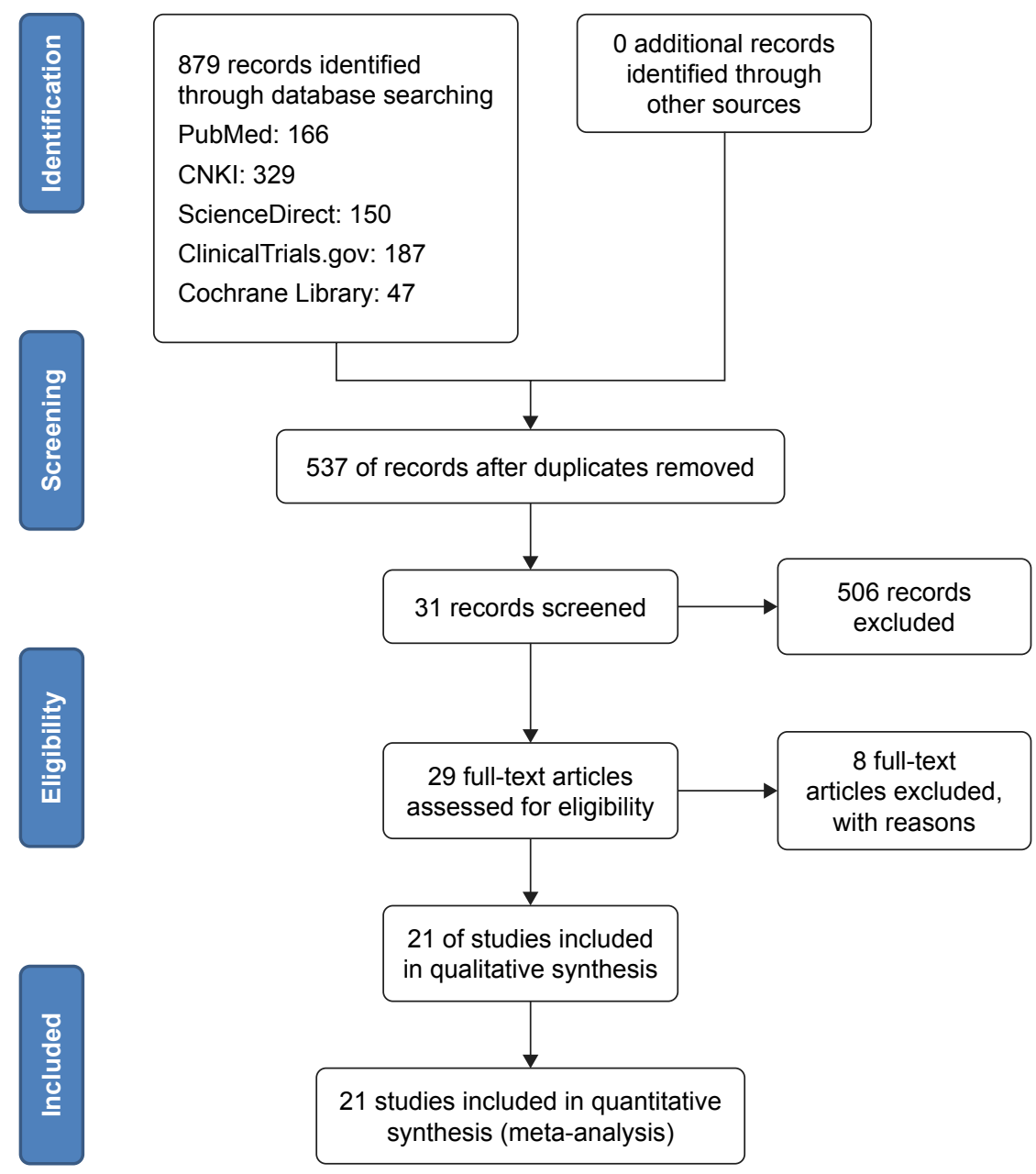

Figure I Flowchart of the article selection process.

exhibited an increased DCR compared with patients who received $<750 \mathrm{mg}(62 \%, 95 \% \mathrm{CI}: 53 \%-71 \%$ vs $33 \%, 95 \% \mathrm{CI}$ : $19 \%-48 \%$; Figure 3A). The pooled ORR of apatinib for liver cancer patients was 18\% (95\% CI: 13\%-24\%; Figure 3B).

\section{Apatinib in gastric cancer}

Five studies with a total of 129 patients evaluated the efficacy of apatinib in gastric cancer. The pooled DCR of apatinib for gastric cancer patients was 66\% (95\% CI: 52\%-79\%). Subgroup analysis demonstrated that patients who received $850 \mathrm{mg}$ apatinib exhibited an increased DCR compared with those patients who were administered $500 \mathrm{mg}$ apatinib (79\%, 95\% CI: $68 \%-89 \%$ vs 56\%, 95\% CI: 40\%-72\%; Figure 4 A). The pooled ORR of apatinib for gastric cancer patients was 10\% (95\% CI: 5\%-15\%; Figure 4B).

\section{Apatinib in breast cancer}

Three studies with a total of 85 patients evaluated the efficacy of apatinib in breast cancer. The pooled DCR of apatinib for breast cancer patients was 66\% (95\% CI: 55\%-76\%; Figure 5A). The pooled ORR of apatinib for lung cancer patients was 16\% (95\% CI: 6\%-26\%). Subgroup analysis revealed that patients who were administered an $850 \mathrm{mg}$ dose of apatinib exhibited an increased ORR compared with those patients who received $<850 \mathrm{mg}$ apatinib (40\%, 95\% CI: 4\%-76\% vs 14\%, 95\% CI: 4\%-23\%; Figure 5B).

\section{Apatinib in colorectal cancer}

Four studies with a total of 103 patients evaluated the efficacy of apatinib in colorectal cancer. The pooled DCR of apatinib for breast cancer patients was 79\% (95\% CI: $70 \%-87 \%$; Figure 6A). The pooled ORR of apatinib for lung cancer patients was 13\% (95\% CI: 7\%-20\%; Figure 6B).

\section{The safety of apatinib}

AEs mostly occurred in every patient treated with apatinib (84\% CI: 77\%-92\%; Figure 7A); however, most were of 


\begin{tabular}{|c|c|c|c|}
\hline A Study ID & & ES $(95 \% \mathrm{Cl})$ & $\%$ weight \\
\hline Shi, 2017 & & $0.83(0.75,0.92)$ & 32.48 \\
\hline Jiao, 2017 & & $0.75(0.62,0.88)$ & 14.06 \\
\hline Yang, 2017 & & $0.89(0.78,1.00)$ & 19.70 \\
\hline Li, 2016 & & $0.86(0.71,1.00)$ & 11.27 \\
\hline Nie, 2017 & & $0.79(0.63,0.94)$ & 10.45 \\
\hline Fang, 2017 & & $0.75(0.61,0.89)$ & 12.05 \\
\hline Overall $\left(I^{2}=0.0 \%, P=0.516\right)$ & & $0.82(0.77,0.87)$ & 100 \\
\hline $\begin{array}{c}1 \\
-1\end{array}$ & & & \\
\hline
\end{tabular}

\begin{tabular}{|c|c|c|}
\hline Study ID & ES $(95 \% \mathrm{Cl})$ & $\%$ weight \\
\hline$<500 \mathrm{mg}$ & & \\
\hline Shi, 2017 & $0.14(0.06,0.22)$ & 35.41 \\
\hline Li, 2016 & $0.24(0.06,0.42)$ & 8.90 \\
\hline Subtotal $\left(I^{2}=0.0 \%, P=0.319\right)$ & $0.16(0.08,0.23)$ & 44.31 \\
\hline \multicolumn{3}{|l|}{$500 \mathrm{mg}$} \\
\hline Jiao, 2017 & $0.20(0.08,0.32)$ & 17.96 \\
\hline Yang, 2017 & $0.32(0.15,0.49)$ & 10.02 \\
\hline Nie, 2017 & $0.29(0.12,0.45)$ & 9.98 \\
\hline Fang, 2017 & $0.17(0.05,0.29)$ & 17.73 \\
\hline Subtotal $\left(I^{2}=0.0 \%, P=0.421\right)$ & $0.23(0.16,0.29)$ & 55.69 \\
\hline Overall $\left(I^{2}=11.3 \%, P=0.343\right)$ & $0.20(0.14,0.25)$ & 100 \\
\hline $\begin{array}{c}1 \\
-0.488\end{array}$ & 88 & \\
\hline
\end{tabular}

Figure 2 The DCR (A) and ORR (B) of apatinib in the treatment of lung cancer. Note: Weights are from random effects analysis.

Abbreviations: DCR, disease control rate; ES, effect size; ORR, objective response rate.

grades 1-2 and were well tolerated and controlled, including secondary hypertension, hand-foot syndrome, proteinuria, fatigue, mucositis, anemia, leukopenia, thrombocytopenia, increased bilirubin, increased transaminase, diarrhea, vomiting, and rashes. The most common grade 3-4 AEs included secondary hypertension ( $7 \%$ CI: $5 \%-10 \%$; Figure $7 \mathrm{~B})$, handfoot syndrome ( $6 \% \mathrm{CI}: 3 \%-8 \%$; Figure $7 \mathrm{C})$, and proteinuria (4\% CI: 2\%-7\%; Figure 7D).

\section{Publication bias}

Egger's and Begg's tests were performed to evaluate the publication bias of all results in this meta-analysis. The test results were consistent with most of the results in this metaanalysis except the ORR of lung cancer (Egger's test: 0.012; Begg's test: 0.260). Given that Egger's test is more sensitive than Begg's test in evaluating publication bias, ${ }^{30}$ we considered that publication bias exists for the ORR results of lung 


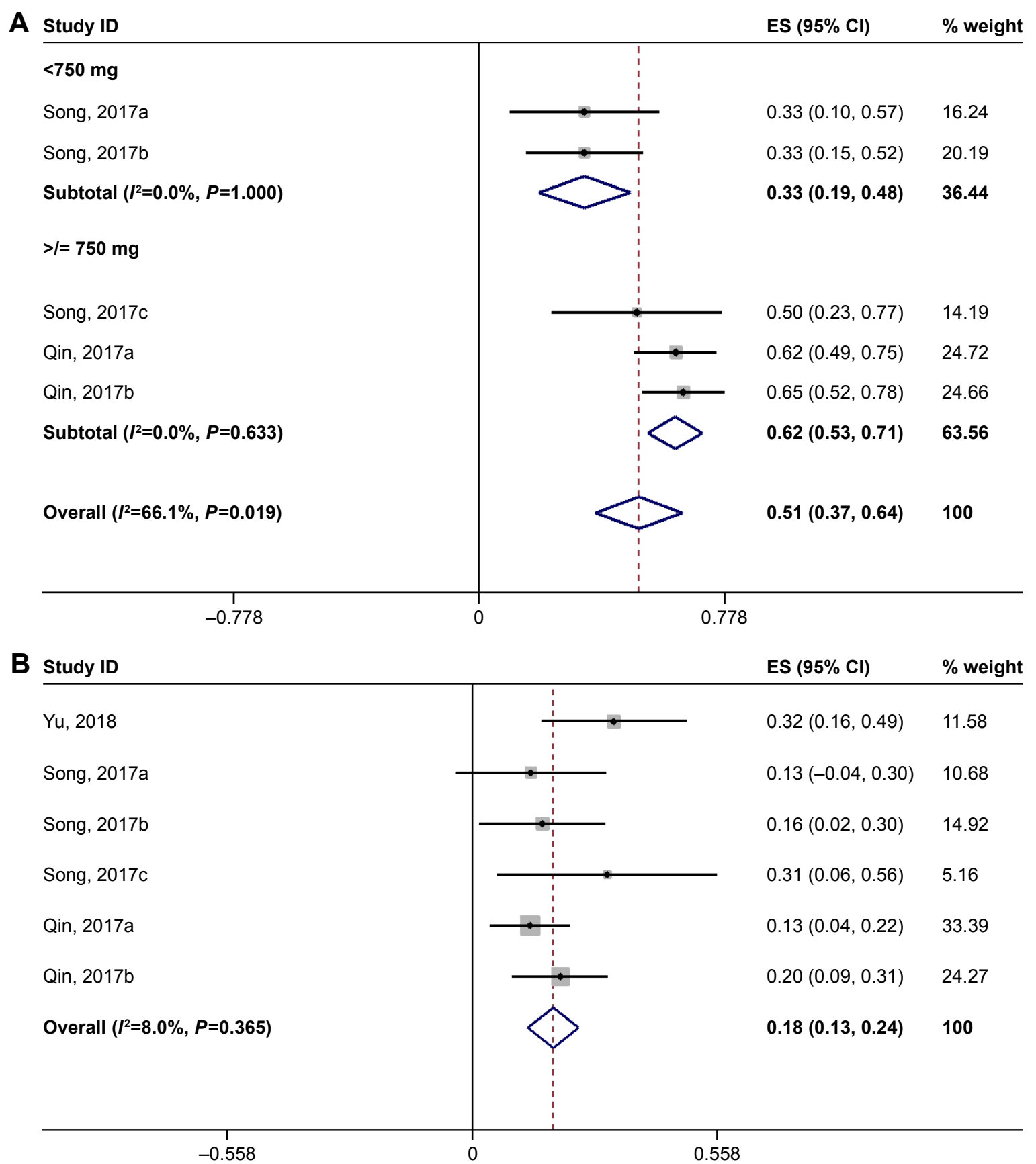

Figure 3 The DCR (A) and ORR (B) of apatinib in the treatment of liver cancer

Note: Weights are from random effects analysis.

Abbreviations: DCR, disease control rate; ES, effect size; ORR, objective response rate.

cancer and the incidence of hypertension and hand-foot syndrome. The publication bias evaluation results are presented in Table S1.

\section{Sensitivity analysis}

The results of sensitivity analysis revealed no significant differences after omitting any one of the studies included, indicating that the results of this meta-analysis were robust. The results of sensitivity analysis are presented in Figures S1-S13.

\section{Discussion}

Apatinib is a selective inhibitor of VEGFR-2 with broadspectrum anticancer effect and is also stated to be involved in the regulation of autophagy. ${ }^{31}$ This meta-analysis involving 21 studies evaluated the efficacy and safety of apatinib in five 
A

Study ID

\section{$850 \mathrm{mg}$}

Ruan, 2017

Lang, 2017

Subtotal $\left(I^{2}=0.0 \%, P=1.000\right)$

$500 \mathrm{mg}$

Zhang, 2017

Zhang, 2016

Yao, 2017

Subtotal $\left(I^{2}=51.6 \%, P=0.127\right)$

Overall $\left(I^{2}=66.3 \%, P=0.018\right)$

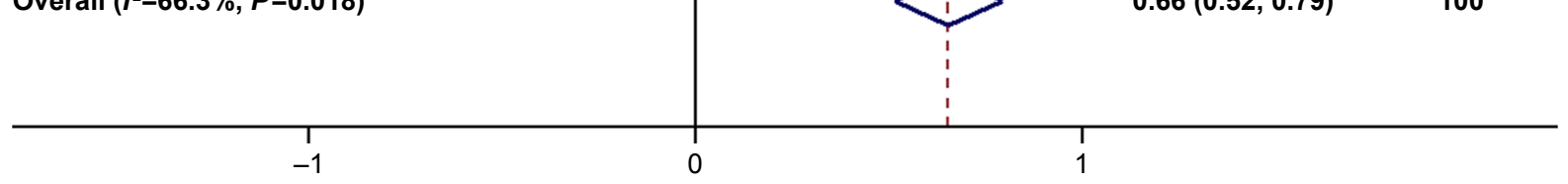

B

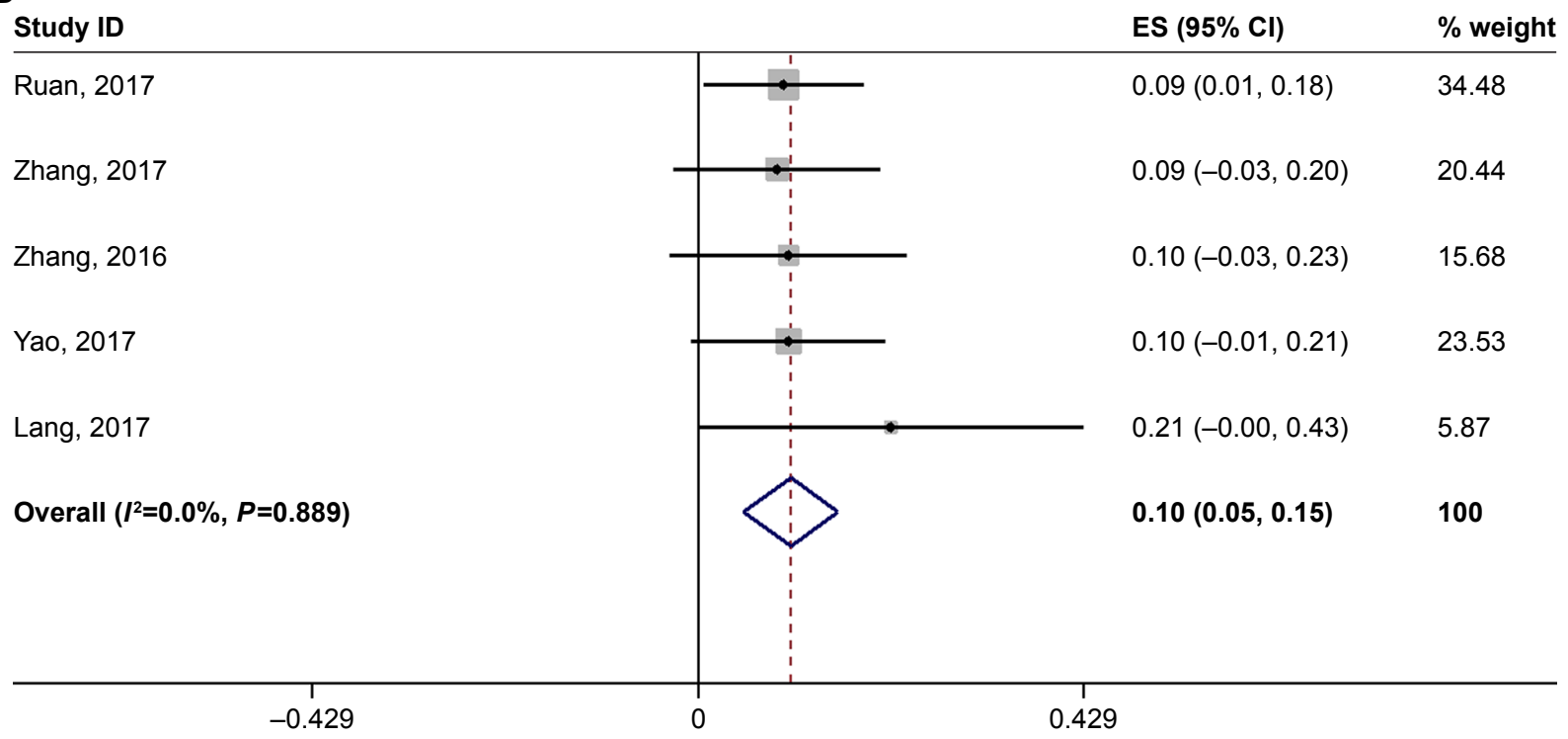

ES $(95 \% \mathrm{Cl}) \quad \%$ weight

$0.79(0.66,0.91) \quad 24.67$

$0.79(0.57,1.00) \quad 17.64$

$0.79(0.68,0.89) \quad 42.31$

$0.70(0.51,0.88) \quad 19.61$

$0.40(0.19,0.61) \quad 17.65$

$0.57(0.39,0.74) \quad 20.43$

$0.56(0.40,0.72) \quad 57.69$

$0.66(0.52,0.79) \quad 100$

Figure 4 The DCR (A) and ORR (B) of apatinib in the treatment of gastric cancer.

Note: Weights are from random effects analysis.

Abbreviations: DCR, disease control rate; ES, effect size; ORR, objective response rate.

major types of solid tumors, namely lung cancer, liver cancer, gastric cancer, breast cancer, and colorectal cancer. The pooled results for the efficacy of apatinib in the treatment of different types of solid tumors revealed that apatinib exhibited good disease control (DCR: lung cancer $82 \%$, liver cancer $51 \%$, gastric cancer $66 \%$, breast cancer $66 \%$, colorectal cancer $79 \%$; ORR: lung cancer $20 \%$, liver cancer $18 \%$, gastric cancer $10 \%$, breast cancer $16 \%$, colorectal cancer $13 \%$ ). In addition, it was likely that a higher dose of apatinib resulted in an increased ORR in lung cancer (500 mg, 23\% vs $<500 \mathrm{mg}, 16 \%$ ) and breast 
A

Study ID

ES $(95 \% \mathrm{CI})$

$\%$ weight

$\mathrm{Hu}, 2014$

Liu, 2017

Yuan, 2017

Overall $\left(I^{2}=6.4 \%, P=0.343\right)$

$-0.94$

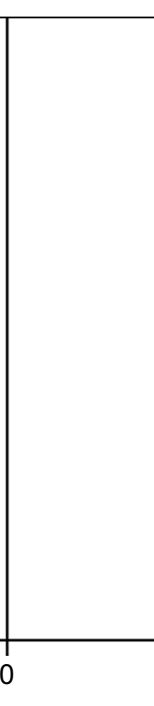

B

Study ID

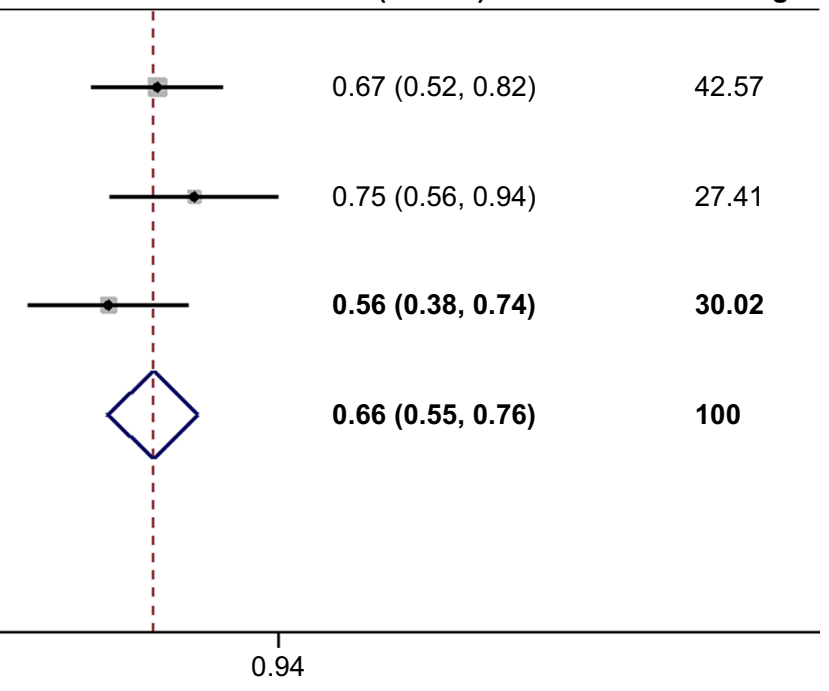

$<850 \mathrm{mg}$

Hu, 2014

Yuan, 2017

Subtotal $\left(I^{2}=0.0 \%, P=0.574\right)$

$850 \mathrm{mg}$

Liu, 2017

Subtotal $\left(I^{2}=\mathrm{NA} \%, P=\mathrm{NA}\right)$

Overall $\left(I^{2}=11.0 \%, P=0.325\right)$

$-0.758$

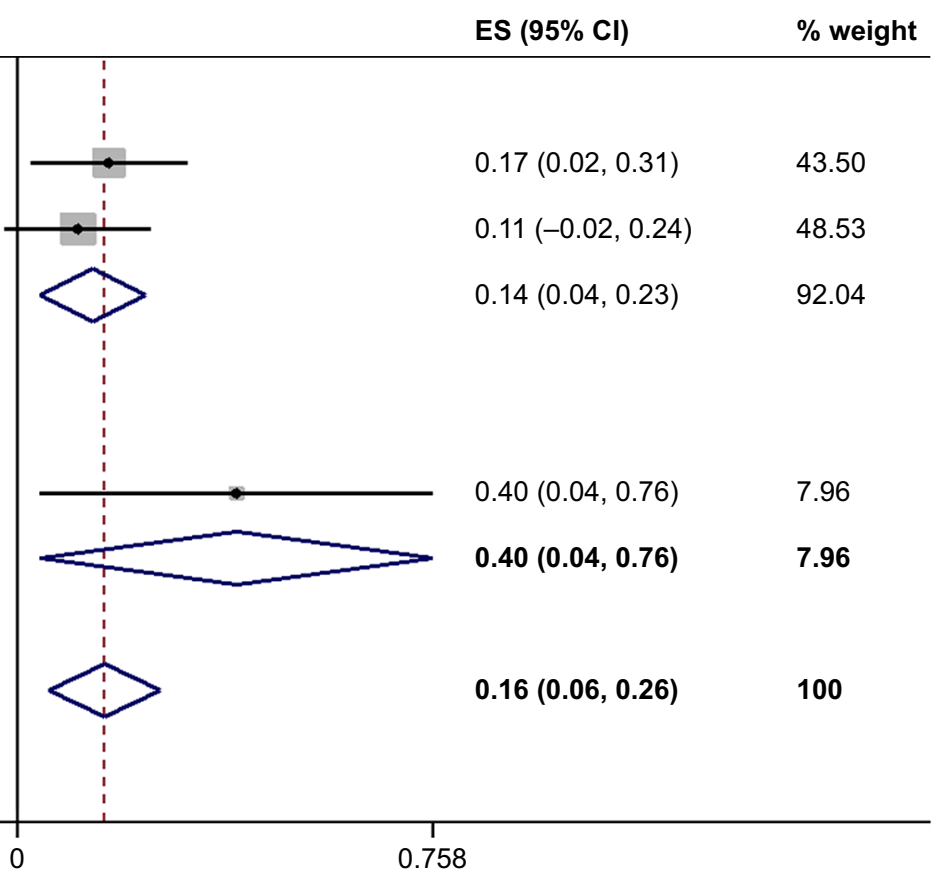

Figure 5 The DCR (A) and ORR (B) of apatinib in the treatment of breast cancer.

Note: Weights are from random effects analysis.

Abbreviations: DCR, disease control rate; ES, effect size; NA, not applicable; ORR, objective response rate.

cancer ( $850 \mathrm{mg}, 40 \%$ vs $<850 \mathrm{mg}, 14 \%$ ), and an increased DCR in liver cancer ( $\geq 750 \mathrm{mg}, 62 \% \mathrm{vs}<750 \mathrm{mg}, 33 \%$ ) and gastric cancer ( $850 \mathrm{mg}, 79 \%$ vs $500 \mathrm{mg}, 56 \%$ ).

Although AEs appeared in $84 \%$ of patients in this metaanalysis, most were of grades 1-2 and were well tolerated and controlled. The most common grade 3-4 AEs were hypertension (7\%), hand-foot syndrome (6\%), and proteinuria (4\%). Importantly, there were no significant differences in these grade 3-4 AEs with higher doses of apatinib (500, 750, and $850 \mathrm{mg}$ ).
In addition to the five major types of solid tumors reported in this meta-analysis, the efficacy of apatinib in other types of solid tumors was also demonstrated by clinical trials. The clinical trials of $\mathrm{Li}$ and $\mathrm{Wang}^{32}$ and Miao et $\mathrm{al}^{33}$ revealed that apatinib is efficacious in esophageal cancer (DCR: 74.2\%; ORR: 24.2\%) and ovarian cancer (DCR: 68.9\%; ORR: 41.4\%), respectively. Apatinib was also found to be effective in prostate cancer ${ }^{34}$ and thyroid cancer. ${ }^{35}$ 
A

Study ID

ES $(95 \% \mathrm{Cl})$

$\%$ weight

Liang, 2018

8

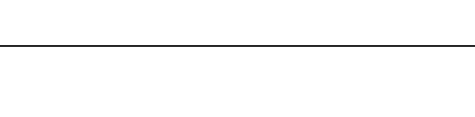

(1)

Gou, 2018

Sun, 2017

Wang, 2017

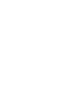

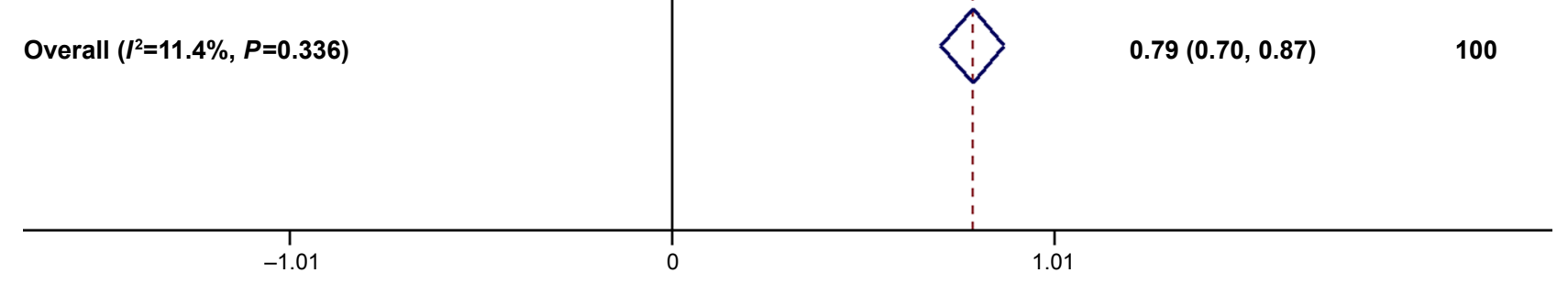

B

Study ID

ES $(95 \% \mathrm{CI})$

$\%$ weight

Liang, 2018

Gou, 2018

Sun, 2017

Wang, 2017

Overall $\left(I^{2}=0.0 \%, P=0.937\right)$

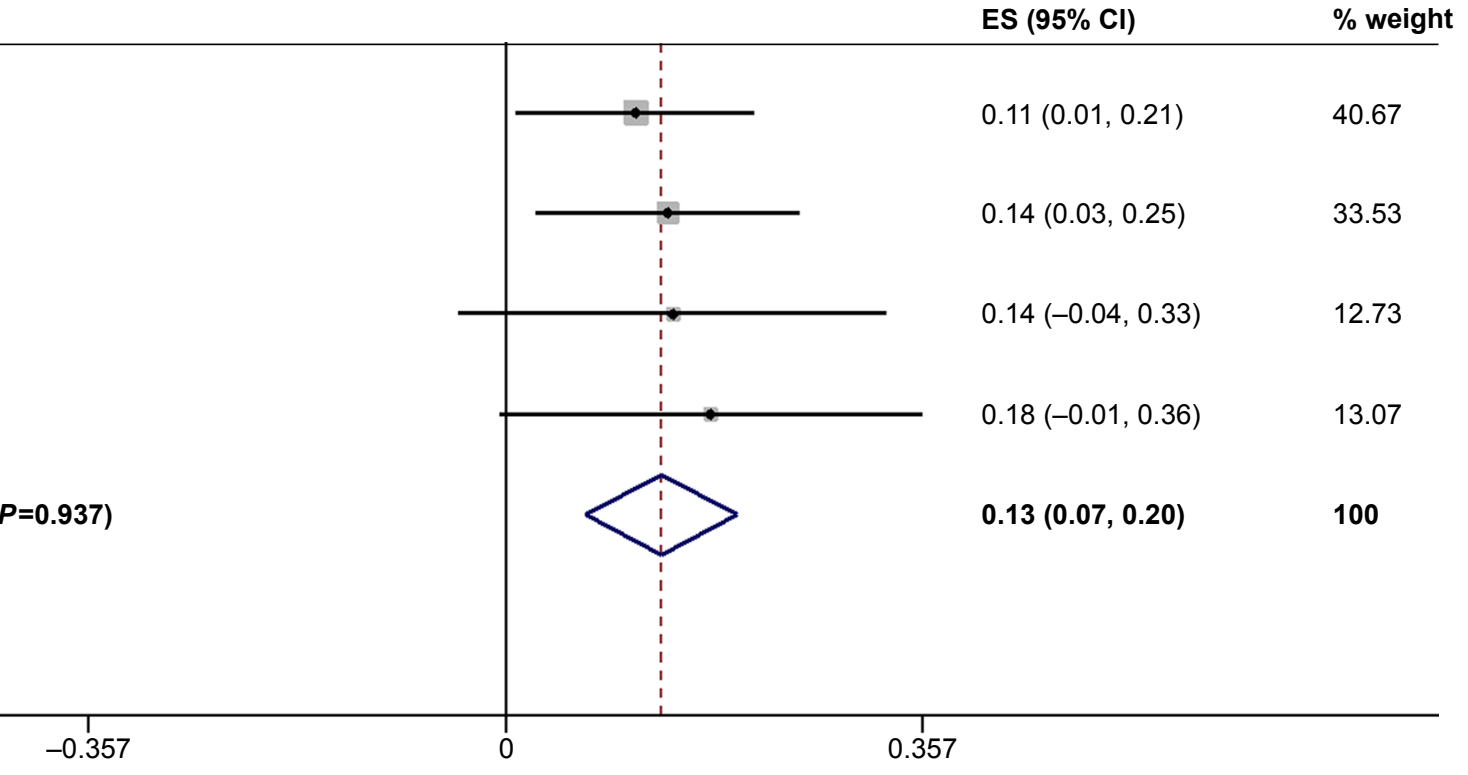

Figure 6 The DCR (A) and ORR (B) of apatinib in the treatment of colorectal cancer. Note: Weights are from random effects analysis.

Abbreviations: DCR, disease control rate; ES, effect size; ORR, objective response rate.

Admittedly, our meta-analysis has some limitations. Given that apatinib is a novel VEGFR-2 inhibitor produced in China, the participants of studies included in this metaanalysis were all Asians. However, some clinical trials have been undergoing in the USA, such as NCT03407976, NCT03396211, and NCT03042611. More data on the efficacy of apatinib in different populations will soon be obtained in the next few years. The efficacy of apatinib for other races must be confirmed by more clinical trials. In addition, publication bias existed in several results of this meta-analysis, including the ORR of lung cancer and the incidence of grade 3-4 hypertension and hand-foot syndrome. Therefore, more clinical trials are needed to confirm our results.

In conclusion, this meta-analysis suggests that patients treated with apatinib exhibited good disease control. A higher dose of apatinib (500, 750, and $850 \mathrm{mg}$ ) significantly increased the ORR and DCR. AEs of apatinib were 
noted in $84 \%$ of participants. However, most AEs were of grades 1-2 and were well tolerated and controlled. The incidences of the three most common grade 3-4 AEs were low (hypertension: 7\%; hand-foot syndrome: $6 \%$; proteinuria: $4 \%$ ), and there were no significant differences between the higher-dose and lower-dose groups. Additional clinical trials are needed to update our study and compare the efficacy of apatinib with other VEGFR-2 inhibitors and other small-molecule tyrosine kinase inhibitors to provide more information to patients.

A

Study ID

ES $(95 \% \mathrm{Cl})$

$0.83(0.75,0.92)$

Shi, 2017

Li, 2017

Overall $\left(I^{2}=0.0 \%, P=0.723\right)$

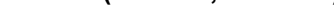

B

Study ID

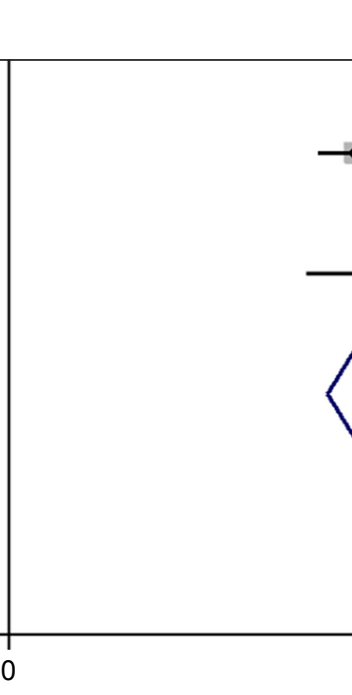

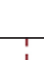

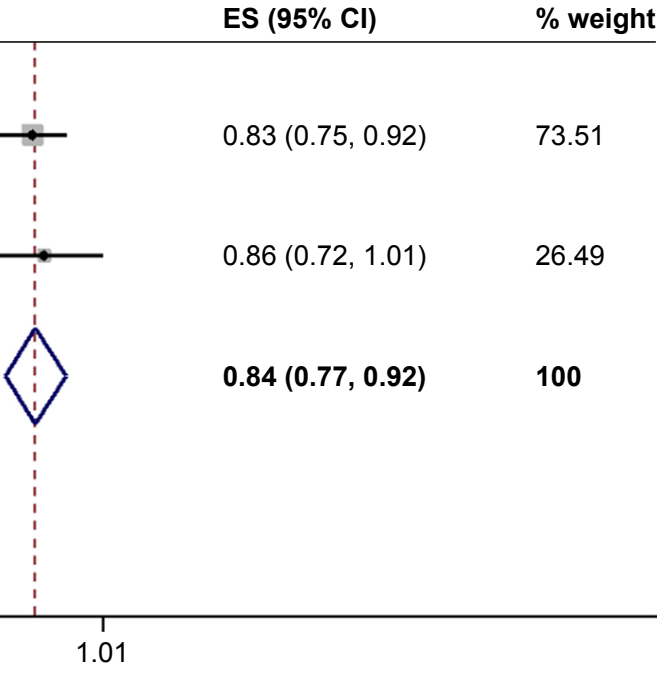

Hu, 2014

Shi, 2017

Yuan, 2017

Jiao, 2017

Yang, 2017

Nie, 2017

Li, 2017

Fang, 2017

Yao, 2017

Lang, 2017

Ruan, 2017

Overall $\left(I^{2}=0.0 \%, P=0.567\right)$

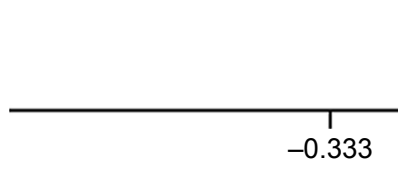

\section{ES $(95 \% \mathrm{Cl})$}

$0.20(0.08,0.33)$

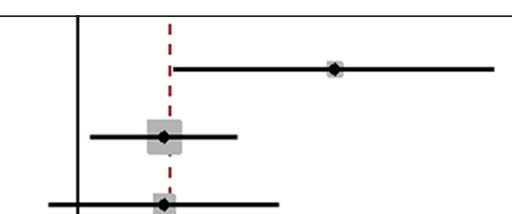

$0.07(0.01,0.13)$

$0.07(-0.02,0.16)$

7.59

$0.08(-0.00,0.15)$

10.17

$0.03(-0.03,0.10)$

15.80

$0.07(-0.02,0.17)$

7.04

$0.05(-0.04,0.13)$

8.60

$0.17(0.05,0.29)$

4.35

$0.07(-0.02,0.16)$

8.07

$0.11(-0.01,0.22)$

4.92

$0.07(-0.01,0.15)$

10.70

$0.07(0.05,0.10)$

100

Figure 7 (Continued) 
C

Study ID

ES $(95 \% \mathrm{Cl})$

$\%$ weight

Hu, 2014

Shi, 2017

Yuan, 2017

Jiao, 2017

Nie, 2017

Fang, 2017

Yao, 2017

Lang, 2017

Ruan, 2017

Yang, 2017

Li, 2017

Overall $\left(I^{2}=0.0 \%, P=0.669\right)$

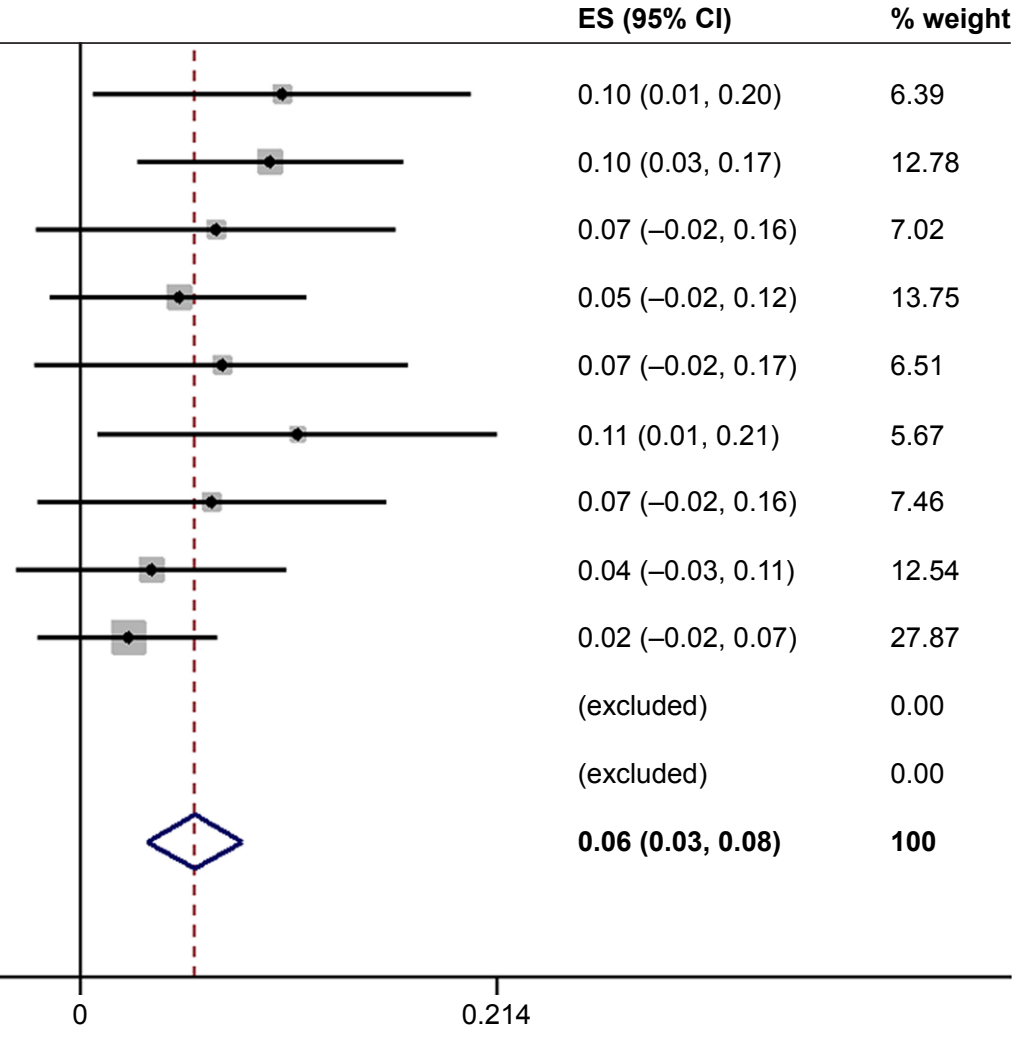

D

$\begin{array}{ccc}1 & 0 & 0.214\end{array}$

Study ID

ES $(95 \% \mathrm{Cl})$

$\%$ weight

$\mathrm{Hu}, 2014$

Shi, 2017

Nie, 2017

Li, 2017

Fang, 2017

Lang, 2017

Yuan, 2017

Jiao, 2017

Yang, 2017

Yao, 2017

Ruan, 2017

Overall $\left(I^{2}=0.0 \%, P=0.999\right)$

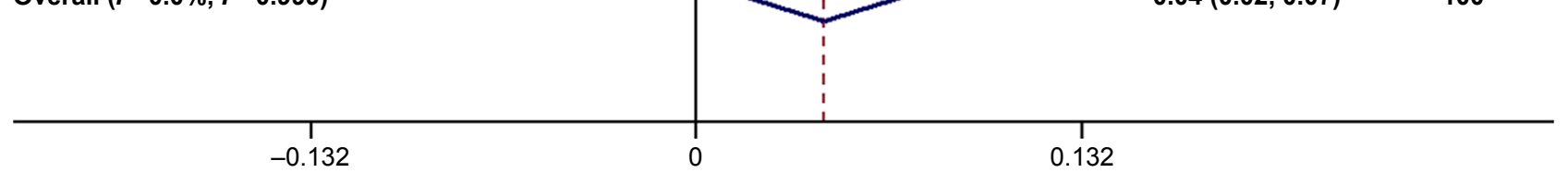

Figure 7 The total incidence of AEs and incidence of grade 3-4 AEs associated with apatinib treatment.

Notes: (A) AEs; (B) hypertension; (C) hand-foot syndrome; (D) protein uria. Weights are from random effects analysis.

Abbreviations: $A E$, adverse event; $E S$, effect size. 


\section{Acknowledgments}

This work was supported by the Taishan Scholar Foundation of Shandong Province (No tshw201502061), the Qingdao People's Livelihood Science and Technology Program (16-6-2-3-nsh), and the Qingdao Entrepreneurial Innovation Leading Talent Program.

\section{Disclosure}

The authors report no conflicts of interest in this work.

\section{References}

1. Chen W, Sun K, Zheng R, et al. Report of cancer incidence and mortality in different areas of China, 2014. Zhongguo Zhong Liu. 2018;27:1-14.

2. Folkman J, Merler E, Abernathy C, Williams G. Isolation of a tumor factor responsible for angiogenesis. $J$ Exp Med. 1971;133(2):275-288.

3. Homsi J, Daud AI. Spectrum of activity and mechanism of action of VEGF/PDGF inhibitors. Cancer Control. 2007;14(3):285-294.

4. Schenone S, Bondavalli F, Botta M. Antiangiogenic agents: an update on small molecule VEGFR inhibitors. Curr Med Chem. 2007;14(23):2495-2516.

5. Roskoski R. Vascular endothelial growth factor (VEGF) and VEGF receptor inhibitors in the treatment of renal cell carcinomas. Pharmacol Res. 2017;120:116-132.

6. Lu W, Ke H, Qianshan D, Wu L, He K, Ding Q, et al. Apatinib has anti-tumor effects and induces autophagy in colon cancer cells. Iran $J$ Basic Med Sci. 2017;20(9):990-995.

7. Zhang H. Apatinib for molecular targeted therapy in tumor. Drug Des Devel Ther. 2015;9:6075-6081.

8. Hu X, Cao J, Hu W, et al. Multicenter phase II study of apatinib in non-triple-negative metastatic breast cancer. 2014;14:820.

9. Liu K, Wu Y. Single arm and single center phase II clinical research of target drug apatinib as third-line treatment of advanced breast cancer. J Med Theor\&Pra. 2017;30:320-322.

10. Yuan L, Liu J, Qin L, et al. Clinical efficacy of apatinib in patients with heavily pretreated metastatic breast cancer. Ai Zheng Jin Zhan. 2017;4:411-415

11. Shi M, Wang S, Xu Z, et al. Effect of apatinib on the advanced nonsmall cell lung cancer. J Clin Pathol Res. 2017;37:1880-1886.

12. Jiao J, Li M. Clinical Evaluation of Apatiinib in the treatment of Advanced Non-Small Cell Lung Cancer. Lin Chuang Yi Yao Wen Xian Za Zhi. 2017;4:11821-11822.

13. Yang M. Efficacy of apatinib in second-line treatment failure of advanced non-small cell lung cancer. Lin Chuang Hui Cui. 2017;32:877-880.

14. Li L, Zhang W, Wang X, et al. Recent clinical observation in treatment of chemotherapy-failed advanced lung adenocarcinoma cases with apatinib. Zhongguo Zong He Lin Chuang. 2016;32:917-920.

15. Nie F, Wang Y, Wang J, et al. Short-term efficacy of apatinib in the third-line treatment of advanced lung adenocarcinoma. Zhongguo $\mathrm{Yi}$ Yao Zhi Nan. 2017;15:157-159.

16. Fang S, Zhang M, Wei G, et al. Apatinib as a third- or further-line treatment in patients with advanced NSCLC harboring wild-type EGFR. Oncotarget. 2018;9:7175-7181.
17. Ruan H, Dong J, Zhou X, et al. Multicenter phase II study of apatinib treatment for metastatic gastric cancer after failure of second-line chemotherapy. Oncotarget. 2017;8:104552-104559.

18. Zhang Y, Gou M, Han C, et al. Efficacy and safety of apatinib as secondline therapy for advanced gastric cancer: a single-center observational study. Anti-Cancer Drug. 2018;29:184-189.

19. Zhang C, Sun G, Hao J, et al. Clinical observation of apatinib mesylate as third-line or above treatment for patients with advanced gastric adenocarcinoma. Lin Chuang Zhong Liu Xue Za Zhi. 2016;21:1114-1117.

20. Yao Y, He Y, Hu B, et al. Clinical observation of treatment in advanced gastric cancer with apatinib. Chin J Cancer Prev Treat. 2017;24:389-393.

21. Lang F, Zhao Y, Fan P, et al. Clinical efficacy and safety of apatinib for patients with advanced gastric cancer. Shi Yong Ai Zheng Za Zhi. 2017; 32:996-998.

22. Yu W, Zhang K, Chen S, et al. Efficacy and safety of apatinib in patients with intermediate/advanced hepatocellular carcinoma: A prospective observation study. Medicine. 2018;97:e9704.

23. Song J, Chen Y, Xu C, et al. Effect of apatinib on treatment of 53 cases of advanced primary liver cancer. J Clin Pathol Res. 2017;37:557-563.

24. Qin S, Bai Y, Ouyang X, et al. Apatinib for patients with advanced hepatocellular carcinoma: a randomised, open-label, multicentre, phase II clinical trial. Lin Chuang Zhong Liu Xue Za Zhi. 2017;22:1057-1065.

25. Liang L, Wang L, Zhu P, et al. A pilot study of apatinib as third-line treatment in patients with heavily treated metastatic colorectal cancer. Clin Colorectal Canc. 2018;17(3):e443-e449.

26. Gou M, Si H, Zhang Y, et al. Efficacy and safety of apatinib in patients with previously treated metastatic colorectal cancer: a realworld retrospective study. Sci Rep-UK. 2018;8:4602.

27. Sun $\mathrm{P}$, Zhang L, Zhang T, et al. Efficacy of single-agent apatinib on advanced colorectal cancer patients failed in second and above chemotherapy. Lin Chuang Zhong Liu Xue Za Zhi. 2017;22:646-649.

28. Wang L, Lu J, Liu Y, et al. A retrospective analysis of the safety and efficacy of apatinib in treating advanced metastatic colorectal cancer. Oncol Transl Med. 2017;3:210-216.

29. Stang A. Critical evaluation of the Newcastle-Ottawa scale for the assessment of the quality of nonrandomized studies in meta-analyses. Eur J Epidemiol. 2010;25:603-605.

30. Hayashino Y, Noguchi Y, Fukui T. Systematic evaluation and comparison of statistical tests for publication bias. J Epidemiol. 2005; 15:235.

31. Lu W, Ke H, Qianshan D, et al. Apatinib has anti-tumor effects and induces autophagy in colon cancer cells. Iran J Basic Med Sci. 2017; 20:990-995.

32. Li J, Wang L. Efficacy and safety of apatinib treatment for advanced esophageal squamous cell carcinoma. Oncotargets Ther. 2017; 10:3965-3969.

33. Miao M, Deng G, Luo S, et al. A phase II study of apatinib in patients with recurrent epithelial ovarian cancer. Gynecol Oncol. 2018; 148:286-290.

34. Zhao F, Tian W, Zeng M, et al. Apatinib alone or combined with radiotherapy in metastatic prostate cancer: Results from a pilot, multicenter study. Oncotarget. 2017;8:110774-110784.

35. Chen K, Gao Y, Shi F, Cao G, Bao J. Apatinib-treated advanced medullary thyroid carcinoma: a case report. Onco Targets Ther. 2018; 11:459-463. 


\section{Supplementary materials Publication bias}

Table SI The Begg's and Egger's tests of the results in this metaanalysis

\begin{tabular}{l|l|l|l}
\hline Results & $\begin{array}{l}\text { Begg's } \\
\text { tests }\end{array}$ & $\begin{array}{l}\text { Egger's } \\
\text { tests }\end{array}$ & $\begin{array}{l}\text { Publication } \\
\text { bias }\end{array}$ \\
\hline Breast cancer ORR & 0.296 & 0.182 & $(-)$ \\
Breast cancer DCR & 1.000 & 0.962 & $(-)$ \\
Colorectal cancer ORR & 0.734 & 0.206 & $(-)$ \\
Colorectal cancer DCR & 0.308 & 0.190 & $(-)$ \\
Gastric cancer ORR & 0.221 & 0.062 & $(-)$ \\
Gastric cancer DCR & 0.806 & 0.293 & $(-)$ \\
Liver cancer ORR & 0.452 & 0.200 & $(-)$ \\
Liver cancer DCR & 0.806 & 0.150 & $(-)$ \\
Lung cancer ORR & 0.260 & $0.012^{*}$ & $(+)$ \\
Lung cancer DCR & 1.000 & 0.386 & $(-)$ \\
Total AEs & 1.000 & - & $(-)$ \\
Proteinuria & 0.348 & 0.600 & $(-)$ \\
Hypertension & 0.005 & $0.007^{*}$ & $(+)$ \\
Hand-foot syndrome & 0.029 & $0.013^{*}$ & $(+)$ \\
\hline
\end{tabular}

Note: *Publication bias exists.

Abbreviations: $A E$, adverse event; $D C R$, disease control rate; ORR, objective response rate.

\section{Sensitivity analysis}

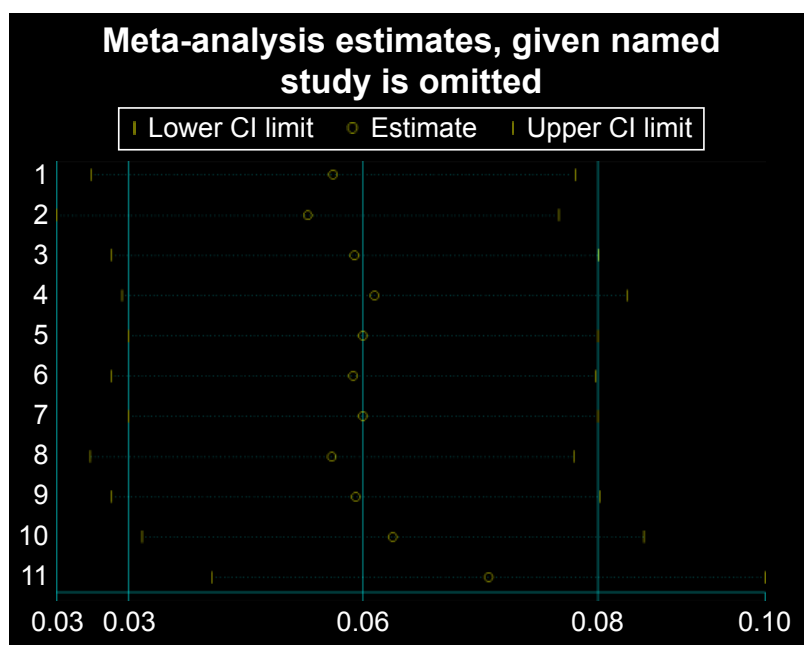

Figure SI Hand-foot syndrome.
Meta-analysis estimates, given named study is omitted

। Lower Cl limit o Estimate | Upper Cl limit

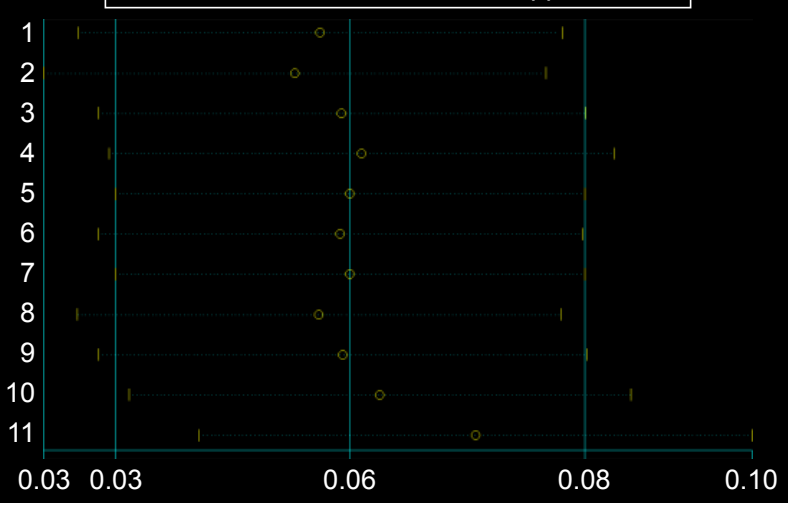

Figure S2 Hypertension.

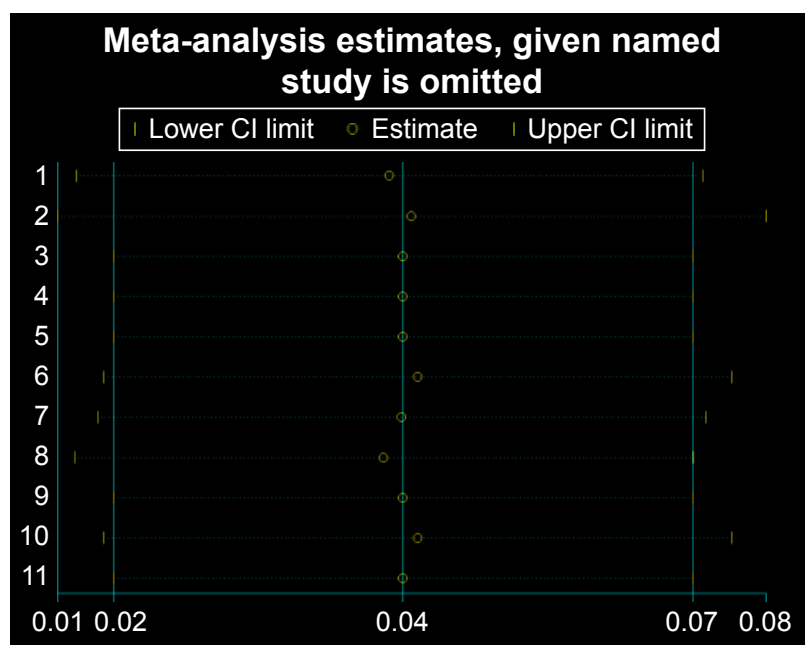

Figure S3 Proteinuria.

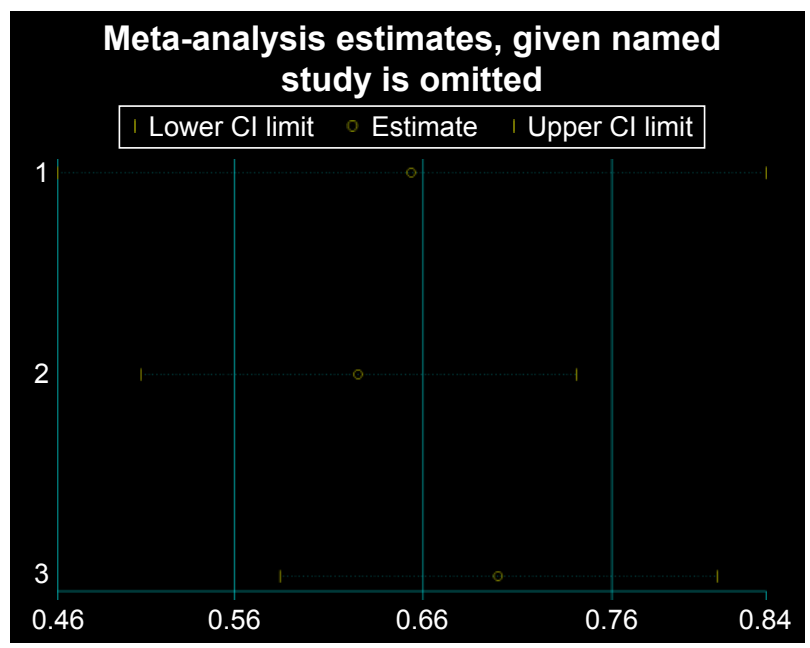

Figure S4 DCR of breast cancer.

Abbreviation: DCR, disease control rate. 


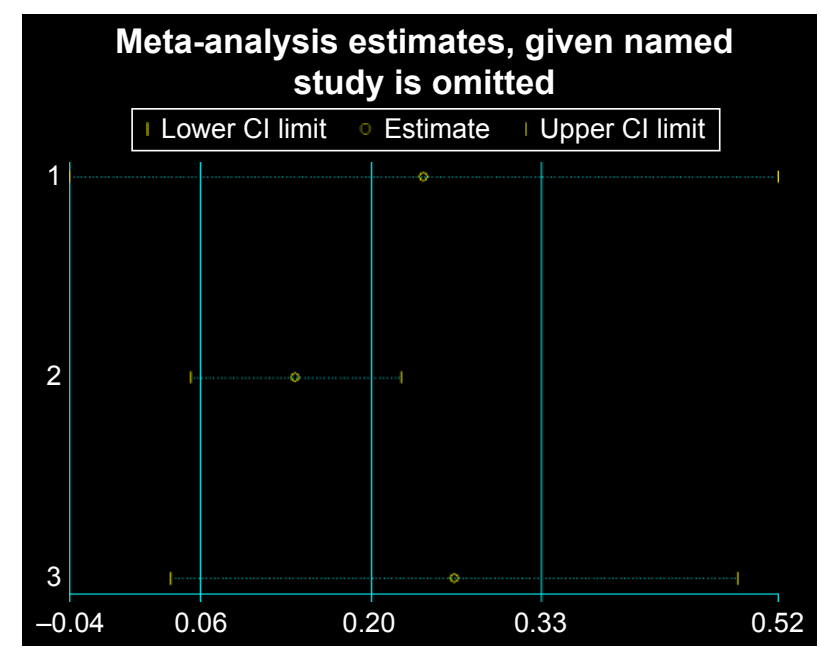

Figure S5 ORR of breast cancer.

Abbreviation: ORR, objective response rate.

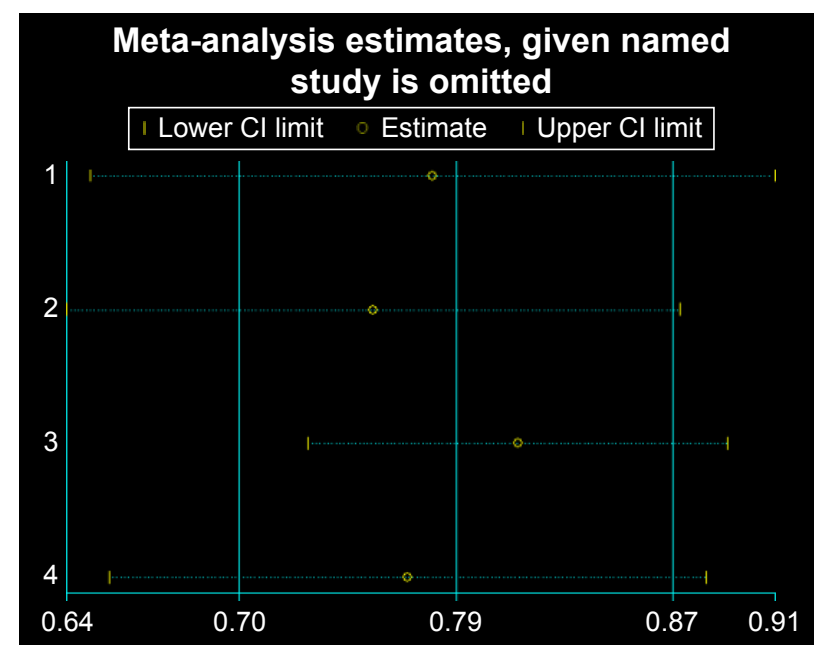

Figure S6 DCR of colorectal cancer.

Abbreviation: DCR, disease control rate.

\section{Meta-analysis estimates, given named} study is omitted

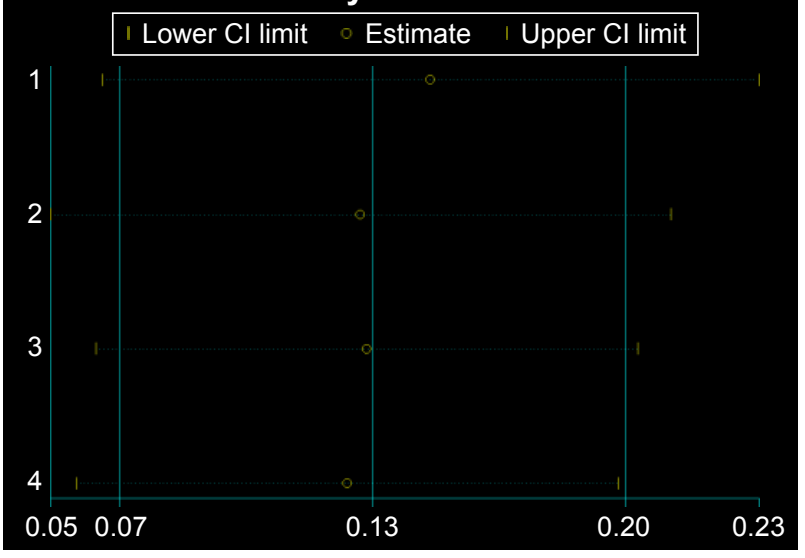

Figure S7 ORR of colorectal cancer.

Abbreviation: ORR, objective response rate.

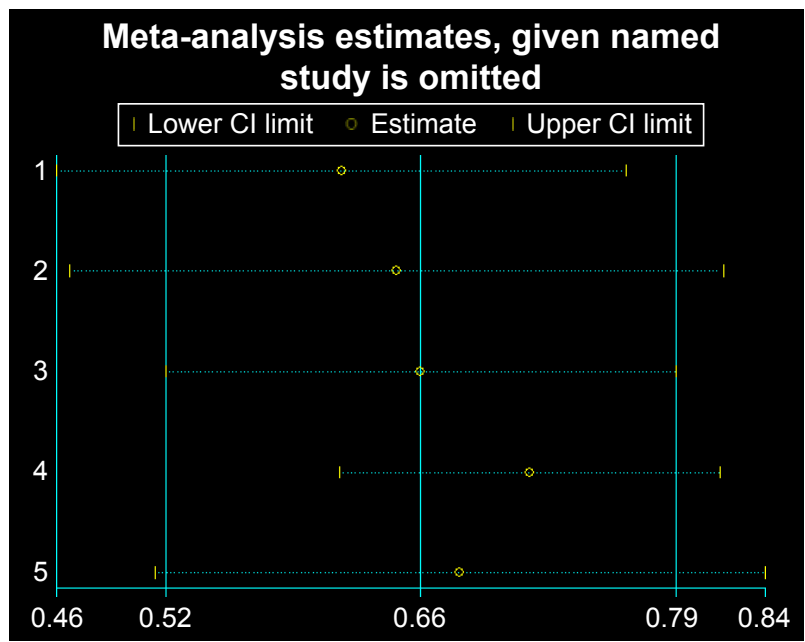

Figure S8 DCR of gastric cancer.

Abbreviation: DCR, disease control rate.

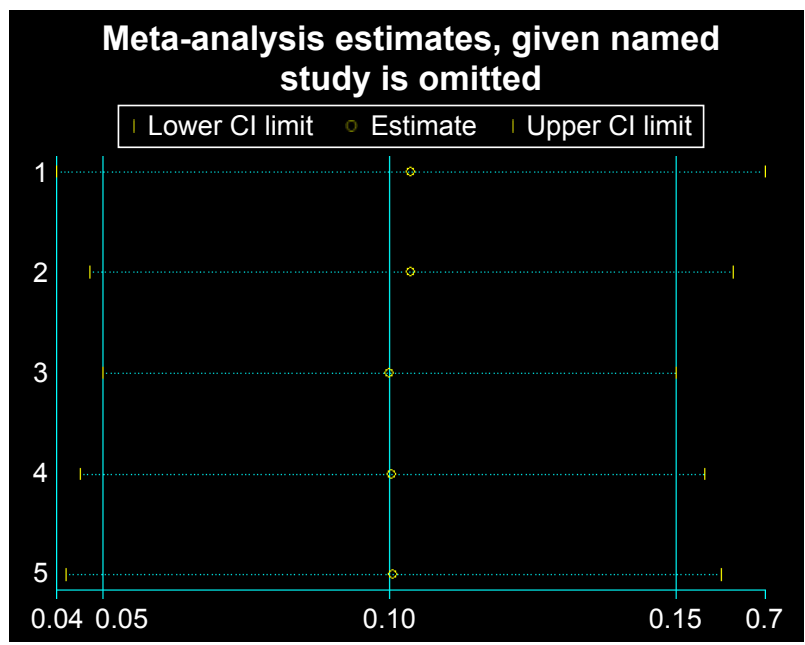

Figure S9 ORR of gastric cancer.

Abbreviation: ORR, objective response rate.

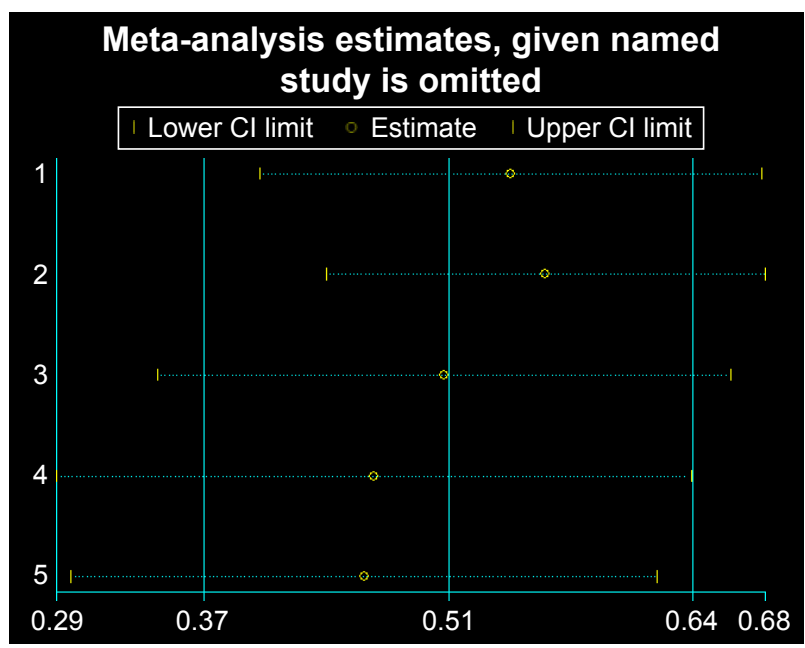

Figure SI 0 DCR of liver cancer

Abbreviation: DCR, disease control rate. 


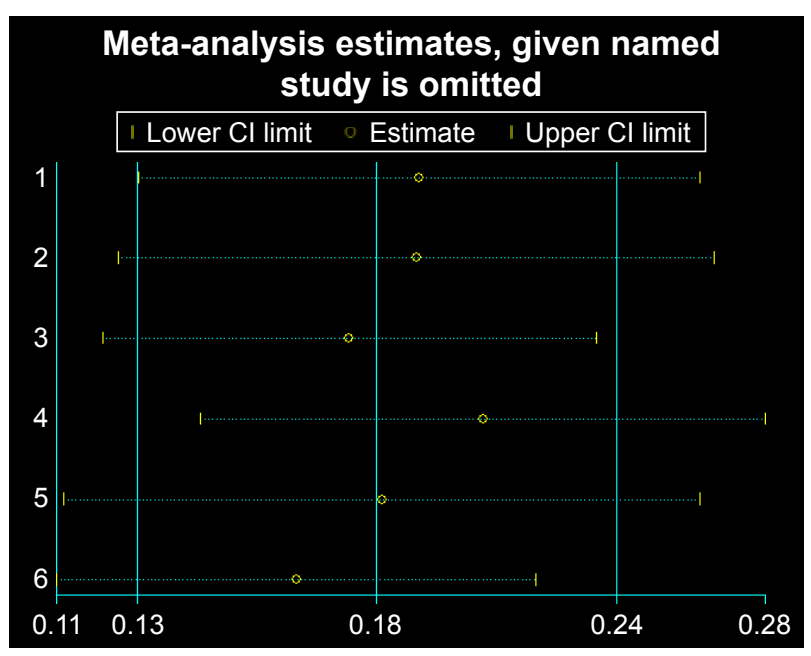

Figure SI I ORR of liver cancer.

Abbreviation: ORR, objective response rate.

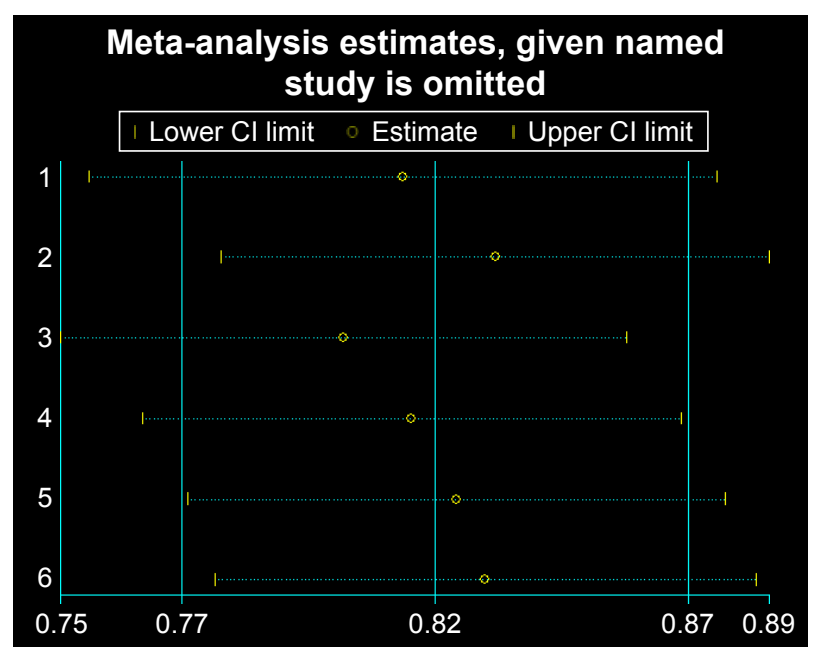

Figure SI2 DCR of lung cancer.

Abbreviation: DCR, disease control rate.

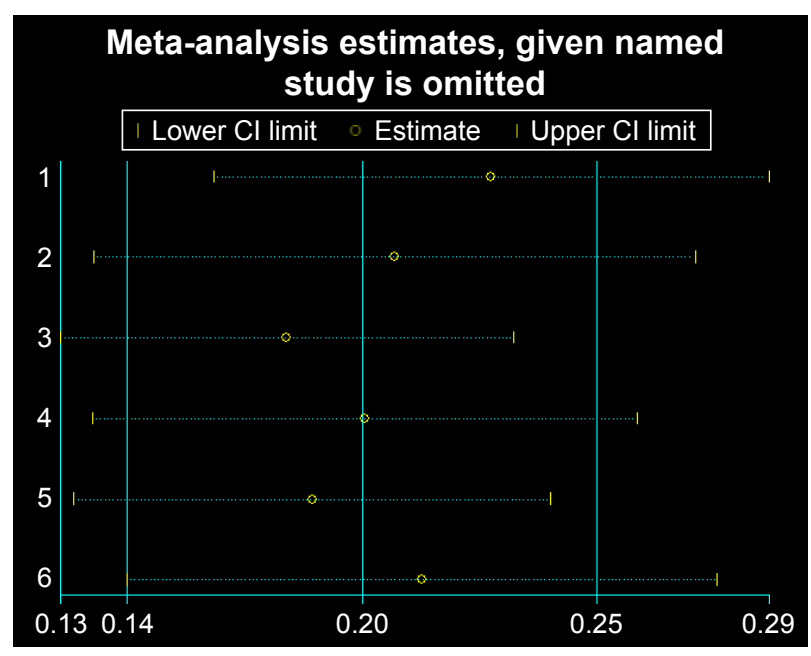

Figure SI 3 ORR of lung cancer.

Abbreviation: ORR, objective response rate.

\section{Publish your work in this journal}

OncoTargets and Therapy is an international, peer-reviewed, open access journal focusing on the pathological basis of all cancers, potential targets for therapy and treatment protocols employed to improve the management of cancer patients. The journal also focuses on the impact of management programs and new therapeutic agents and protocols on

\section{Dovepress}

patient perspectives such as quality of life, adherence and satisfaction. The manuscript management system is completely online and includes a very quick and fair peer-review system, which is all easy to use. Visit http://www.dovepress.com/testimonials.php to read real quotes from published authors. 